\title{
Rare Vascular Surgery in Apollo Hospitals, Dhaka --Right Popletial to Dorsalis pedis Artery Anastomosis and Axillary Bi Femoral Bi Poplileal Bypass Grafting - limb salvage procedure
}

\author{
NM Zahangir ${ }^{1}$, Nazmul ${ }^{2}$, TMNS Khan ${ }^{3}$, RA Chowdury ${ }^{4}$, Z Haider ${ }^{5}$.
}

\begin{abstract}
Bypass grafts to the dorsalis pedis artery provide excellent revascularization to ischemic foot. It is a durable and effective procedure for limb salvage. Axillo femoral-popliteal procedure offers a reasonable alternative in high-risk patients. We are reporting 2 cases of such procedures from Apollo hospitals, Dhaka. Right Popletial to Dorsalis pedis artery anastomosis was done in a 32 years old man. Interposition venous graft was done from the right popliteal artery to dorsalis pedis artery. Axillo-Bi Femoral-Bi Poplileal Bypass Grafting: was done in a 59 years old man. Knitted fabric strength graft was used. Both the patients were doing well in postoperative period.
\end{abstract}

\section{Introduction}

In critically ischemic foot, Dorsalis pedis artery bypass is a durable and effective procedure for limb salvage. ${ }^{1}$ Dorsalis pedis bypass is reliable with a great chance of ischemic foot salvage over years. Saphenous vein is the preferred conduit. Good results authenticate routine use of pedal arterial reconstruction for patients with ischemic foot complications.

Extra-anatomic vascular reconstructions have been introduced as alternative procedures for the elderly or high risk patient, in whom a standard transabdominal aorto-femoral bypass would imply prohibitive perioperative morbidity or mortality. ${ }^{2}$ As time went on and larger series of Extra-anatomic vascular reconstructions have been published, it became evident that long term results are quite satisfactory.

\section{Case report 1}

Right Popletial to Dorsalis pedis artery anastomosis:

A 32 years old non diabetic, non hypertensive heavy smoker gentleman came to our hospital with arterial occlusive disease of right lower limb with gangrene of right great and little toes. According to the patient, the problem began two years back with claudication pain. For the last eight months pain has gradually increased. Angiogram revealed both anterior and posterior tibial arteries are occluded. Operation was done on 20.04.2011. We explored the right popliteal artery and dorsalis pedis artery. Tunnelar was passed through subcutaneous tissue from popliteal artery to dorsalis pedis artery (Figure1). Saphenous vein from left leg was harvested and interposition venous graft was done from the right popliteal artery to dorsalis pedis artery (Figure 2). Dorsalis pedis artery was nicely palpable (Figure 3) and the right lower limb was warm oxygen saturation was $100 \%$ of the limb. On 27.04.2011 on $6^{\text {th }}$ POD, amputation of gangrenous right great \& little toe was done. With a haemo dynamically stable condition he was discharged on 30.04.2011. The patient was doing very well in the $1 \frac{1 / 2}{2}$ months after follow up. 


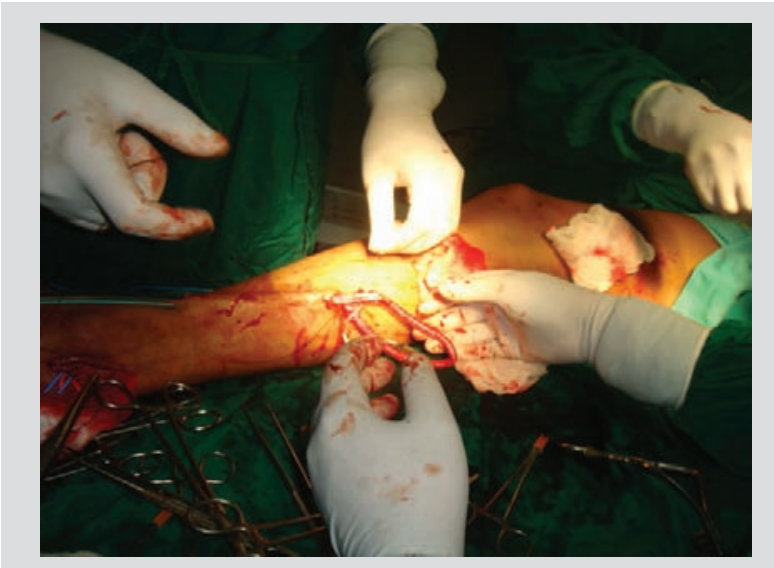

Figure 1: Saphenous vein is passed through subcutaneous tunnel

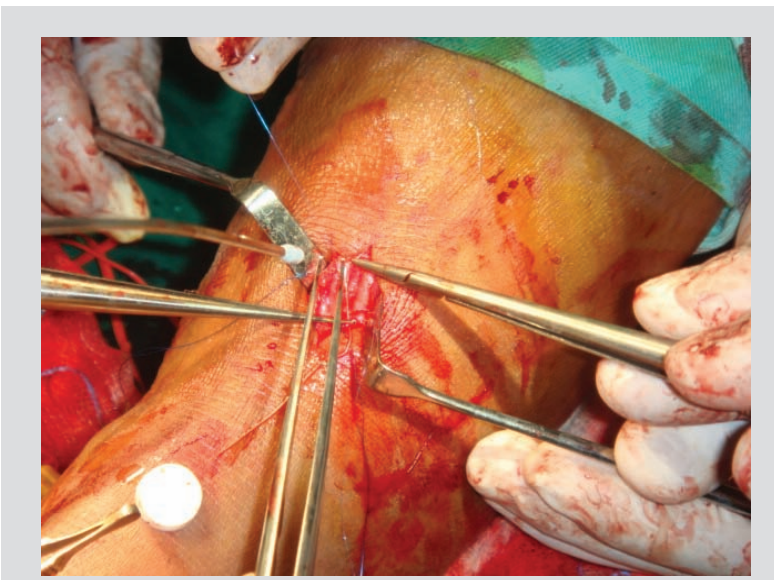

Figure 2: Anastomosis with dorsalis pedis artery

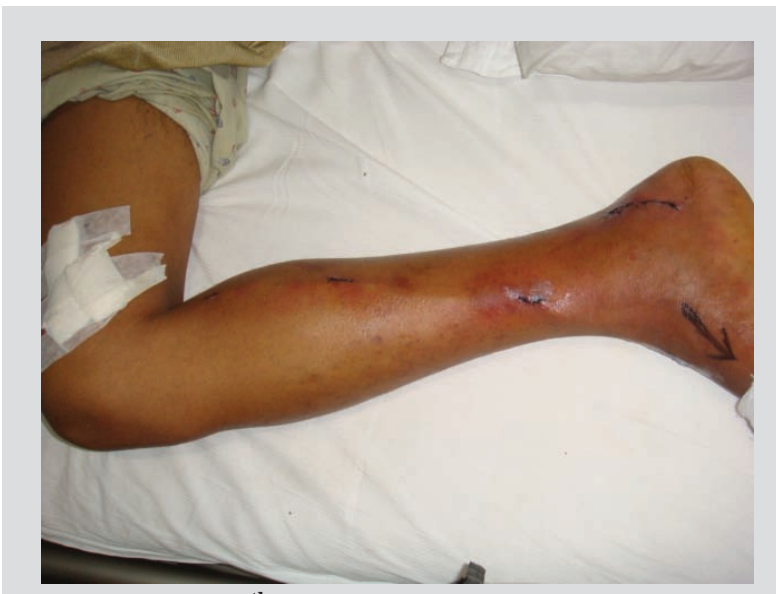

Figure 3: $5^{\text {th }}$ postoperative day with good pulsation in dorsalis pedis artery

\section{Case report 2}

Axillo-Bi Femoral-Bi Poplileal Bypass Grafting as limb salvage procedure:A 59 years old, hypertensive, diabetic, dyslipidaemic gentleman who is a smoker got admitted with severe pain on both lower limbs for 2 months. His CABG was done in 2007. He had history of coronary stenting. He was also suffering from acute left ventricular failure at the time of admission which was treated conservatively in CCU. Ejection fraction was low (35\%). Angiogram showed atherosclerotic lesion in iliac arteries and femoral arteries.

Operation was done on 03.05.2011. Left Axillary artery, both femoral arteries and popliteal arteries were explored. Subcutaneous tunnel was done through left mid axillary line (Figure 4) to both femoral arteries and popliteal arteries (Figure 5). Knitted fabric strength graft $(6 \mathrm{~cm} \times 40 \mathrm{~mm})$, and (7cm x $40 \mathrm{~mm})$ was anastomosed from Left Axillary artery to both femoral arteries and popliteal arteries (Axillo-Bi Femoral-Bi Poplileal Bypass Grafting) (Figure 6).

The post operative period was uneventful. The patient was doing well in his 2 months postoperative follow up.

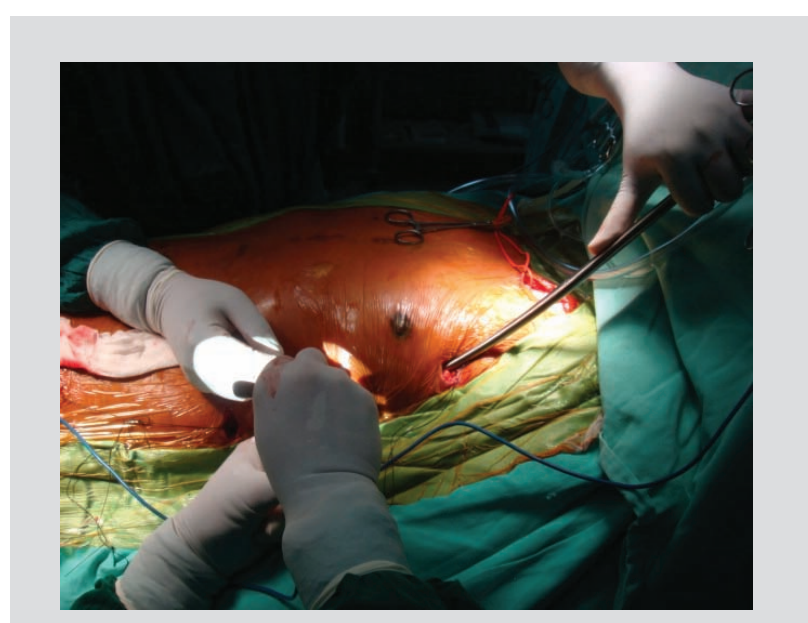

Figure 4: Subcutaneous tunneling is done through left mid axillary line 


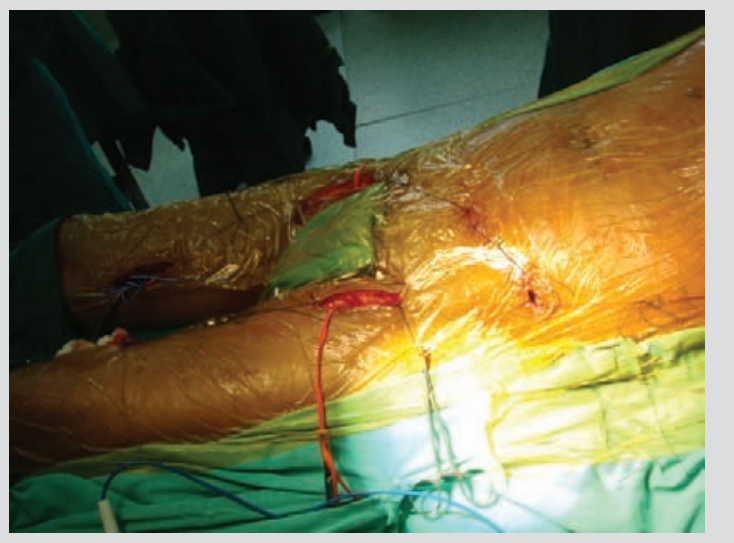

Figure 5: Both femoral arteries and popliteal arteries are exposed and connected by subcutaneous tunnel

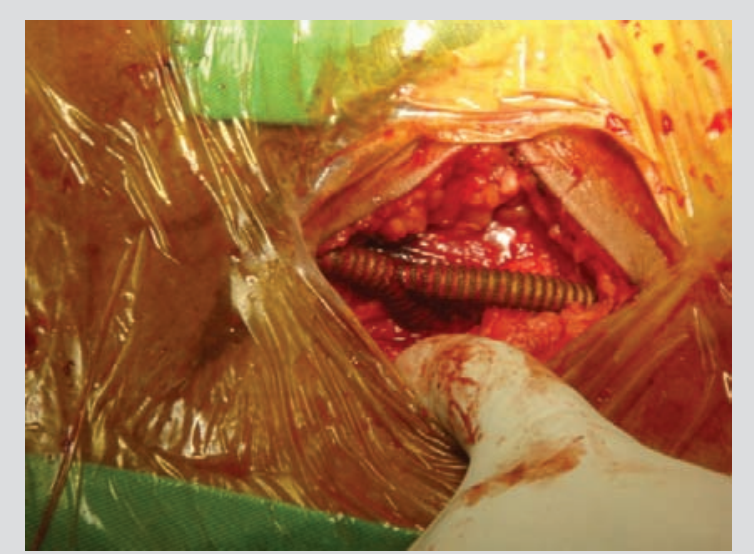

Figure 6: Graft to femoral artery and popliteal artery

\section{Discussion}

Pedal bypass provides durable and effective limb salvage for ischemic foot lesions. Saphenous vein is the preferred conduit when available. Short vein grafts from distal inflow sites are possible. These results justify the routine use of pedal arterial reconstruction for patients with ischemic foot complications. ${ }^{3}$ Bypass grafts to the dorsalis pedis artery provide substantial perfusion to the foot such that the resulting limb salvage and healing rates for revascularized limb is excellent. Frank B et al had history of four hundred and two patients underwent explo ration for bypass, all procedures were performed with vein. Inflow was taken from the common femoral artery in $34 \%$, popliteal arteries in $60 \%$, a previously placed graft in $5 \%$, and a tibial artery in $1 \%$. Actuarial primary and secondary patency and limb salvage rates were $68 \%, 82 \%$, and $87 \%$, respectively, at 5 years' follow-up. The actuarial patient survival rate was $57 \%$ at 5 years. Dorsalis pedis arterial bypass is an effective limb salvage procedure with long-term durability comparable to distal vein grafts placed into more proximal arteries. ${ }^{4}$ Bypass grafts to the dorsalis pedis artery provide excellent revascularisation to ischemic foot.

In “extra-anatomic bypass” grafts they pass through a different anatomic pathway than do the natural blood vessels they replace. These grafts are devised to circumvent complex problems when conventional vascular procedures are not possible or are too hazardous to perform. Extra-anatomic bypass grafts are an accepted technique with known patency rates. Quality nursing care plays a significant role in successful patient outcome.

Axillo femoral-popliteal procedure offers a reasonable alternative in high-risk patients. Since neither the thoracic nor the abdominal cavity is violated when performing the operation, the procedure usually does not interfere with the patient's ability to breathe, cough, or take oral feedings, which is particularly important in patients who are poor candidates for major surgery. Axillo femoral bypass is an acceptable alternative to AOFB in properly selected high-risk patients with critical lower extremity ischemia who would likely not tolerate the more durable AOFB. ${ }^{5}$

Cumulative graft patency of approximately 70 percent at five years has been obtained with this procedure. 
These results are inferior to those for aorto-femoral bypass. Thus, axillofemoral bypass grafting is usually reserved for high-risk patients with limb threatening ischemia. ${ }^{6}$

In a 12 year study performed by Division of Vascular Surgery, Montefiore Medical Center, New York, axillopopliteal bypass grafting were done in 50 patients with $6 \mathrm{~mm}$ polytetrafluoroethylene grafts for limb salvage who were at high risk for limb loss. Overall 1, 3, and 5 year cumulative primary graft patency rates were $58 \%, 45 \%$, and $40 \%$, respectively. Comparable limb salvage rates were $83 \%, 68 \%$, and $58 \%$. Three-year patency rate for sequential axillofemoral-popliteal grafts was $74 \%$. These results show that axillopopliteal bypass grafting is justified when other standard operations are not possible in patients who are in imminent danger of limb loss, and that every possible effort should be made to use the common or deep femoral artery as part of a sequential axillofemoral-popliteal procedure. ${ }^{7}$

Department of Vascular Surgery, Utrecht University Medical Center, Utrecht, The Netherlands showed results of all axillopopliteal bypass reconstructions over an 11-year period which was analyzed. Thirty axillo-popliteal bypass grafts were performed on 24 patients (mean age 67 years). The primary patency after 1 year was $64 \%$. The secondary patency after 1 year was $77 \%$. Limb salvage after 1 year was $84 \%$. We conclude that extra-anatomical axillopopliteal bypass is a valuable therapeutic option for limb salvage in this specific patient population. ${ }^{8}$

\section{Conclusion}

Dorsalis Pedis artery bypass provides effective limb salvage of ischemic foot lesions for long time. Popliteal-distal artery bypass is a favorable revascularisation procedure with critical limb ischemia. Axillofemoral-popliteal bypass is generally used as a final attempt to save limb. Both procedures are being performed in many centers with good patency and salvage rates.

\section{Reference}

1. Frank BP, Nikhil K, Alan DH, Alana B, Malachi S, David RC. A decade of experience with

dorsalis pedis artery bypass: analysis of outcome in more than 1000 cases. J Vasc Surg.

2003;37:307-15.

2. Blaisdell FW, Hall AD. Axillary-femoral artery bypass for lower extremity ischemia. Surgery. 1963;54:563-568.

3. Frank BP, Edward JM, Gary WG, David RC, Dorothy VF, Anne MB. Dorsalis pedis arterial

bypass: durable limb salvage for foot ischemia in patients with diabetes mellitus. J VASC SURG. 1995;21:375-84.

4. Scott AB, Allen KC, Frank BP, Gary WG, David RC, Cameron MA. Efficacy of dorsal pedal artery bypass in limb salvage for ischemic heel ulcers. J Vasc Surg. 1999;30:499-508.

5. Schneider JR, McDaniel MD, Walsh DB, Zwolak RM, Cronenwett JL. Axillofemoral bypass:outcome and hemodynamic results in high-risk patients. J Vasc Surg. 1992;15(6):952-62.

6. Mannick JA, Whittemore AD. Aortoiliac occlusive disease. In. Moore WS, editor. Vascular Surgery: A comprehensive review. Philadelphia: WB Saunders; 1991. p. 350.

7. Ascer E, Veith FJ, Gupta S. Axillopopliteal bypass grafting: indications, late results, and

determinants of long-term patency. J Vasc Surg. 1989;10(3):285-91.

8. Meta R , Hissinka RJ,Van Reedt Dort landa RWH, Steijlinga JJ, Verhagena $\mathrm{H}$,

Moll FL. A extra-anatomical reconstruction in the case of an inaccessible groin: The axillopopliteal bypass. Ann. of Vasc Surg. 2007;21(2): 240-44. 
CME in Apollo Hospitals Dhaka from July to December 2011

\begin{tabular}{|c|c|c|c|c|}
\hline SL & Date & Topic & Speaker & Department \\
\hline 1 & $27^{\text {th }}$ July 2011 & $\begin{array}{l}\text { "Hearing assessment } \\
\text { \& management of } \\
\text { hearing loss in } \\
\text { Neonates \& } \\
\text { Children". }\end{array}$ & $\begin{array}{l}\text { Dr. Saket Aggarwal } \\
\text { Consultant \& } \\
\text { Coordinator } \\
\text { Dept. of ENT }\end{array}$ & Dept. of ENT \\
\hline 2 & $21^{\text {st }}$ September 2011 & $\begin{array}{l}\text { Update On Viral } \\
\text { Encephalitis }\end{array}$ & $\begin{array}{l}\text { Dr. Alim Akhtar Bhuiyan } \\
\text { Consultant \& Coordinator, } \\
\text { Dept. of Neurology }\end{array}$ & Dept. of Neurology \\
\hline 3 & $19^{\text {th }}$ October 2011 & $\begin{array}{l}\text { Device Management } \\
\text { of Chronic Heart } \\
\text { Failure \& SCD } \\
\text { CTO \& LM STEM PCI }\end{array}$ & $\begin{array}{l}\text { Prof. Dr. Md. } \\
\text { Shahabuddin Talukder } \\
\text { Coordinator \& Consultant } \\
\text { Cardiology } \\
\text { Dr. Abul Hasan } \\
\text { Mohd. Waliul Islam } \\
\text { Specialist-Cardiology }\end{array}$ & Dept. of Cardiology \\
\hline 4 & $23^{\text {rd }}$ November 2011 & Floppy Infant & $\begin{array}{l}\text { Dr. Jesika Mahjabeen } \\
\text { Resident Medical } \\
\text { Officer-Pediatrics }\end{array}$ & Dept. of Pediatrics \\
\hline 5 & $30^{\text {th }}$ November 2011 & $\begin{array}{l}\text { Staphylococcal } \\
\text { Scalded Skin } \\
\text { Syndrome }\end{array}$ & $\begin{array}{l}\text { Dr. Farzana Nahid } \\
\text { Sr. Medical officer- } \\
\text { Pediatrics }\end{array}$ & Dept. of Pediatrics \\
\hline
\end{tabular}




\section{Instruction to Authors}

Pulse is the official medical journal of Apollo Hospitals Dhaka. The aim is to ensure and maintain strong, upto date academic base and share updated medical knowledge, views, and performances.

Papers written in English will be considered for publication provided these have not been published previously and are not under consideration for publication elsewhere.

\section{Conditions for manuscript submission:}

- All manuscripts will be subjected to peer and editorial review.

- Accepted manuscripts become the property of the pulse. Any reproduction in whole or part will require written permission from the editorial board of the journal.

- The author should obtain written permission from appropriate authority if the manuscript contains any table; data or illustration from previously published other journals. The letter of permission should be submitted with the manuscript.

- If the photographs are not disguised, the permission from the patient or parents/guardians to print should accompany the manuscript. Otherwise identity will be blackened out.

- Rejected manuscripts/electronic copies/ illustrations/ photographs will not be returned to the authors.

- Editors are not responsible for electronic/ courier/postal failure.

Manuscript preparation: The editorial board has decided to comply with "Uniform Requirements for Manuscripts Submitted to Biomedical Journals" published by the International Committee of Medical Journal Editors in Vancouver, British Columbia in 1979 (the widely accepted "Vancouver style")' published in the Annals of Internal Medicine 1982;96:766-71. All scientific units should be expressed in System International (SI) units. Authors are referred to Annals of Internal Medicine 1987;106:114-29 for guidance in the use of SI units. All drugs should be mentioned in their generic form.

- Original articles, reviews, special articles, case reports and any other articles of medical interest are welcome.

- Should be typed in English and on one side of A4 $(290$ x 210cm) size white paper, using Times new roman font, size 12, with double space.

- There should be one original and two paper copies and one IBM compatible electronic copy.

- There should be a margin of $2.5 \mathrm{~cm}$ at top and bottom and remainder.

- Pages should be numbered in English numerical at the upper right hand, consecutively, beginning with the title page.

- Manuscripts should be submitted in the following order:

o Title page

o Abstract (should include background, objective, methodology, results, conclusion in short) with key words

o Text (Introduction, Materials \& Methods, Results, Discussion, Conclusion).

o Acknowledgements

o References

\section{- Photographs:}

o Unmounted glossy paper, $12.7 \times 17.3$ size

o Should be clipped to a white paper withappropriate labeling (number in Englishnumerical, title of photo graphs and title of manuscripts.)

\section{- Illustrations:}

o All illustrations should be cited in the text

o Illustration should be numbered in English numerical and labeled properly. 


\section{PULSE OFFICIAL}

- Tables:

o Should not duplicate the text.

o Should be appropriately titled.

o Numbered with roman numerical in order of text.

o Abbreviations if used; should be explained in footnotes.

- Placement:

o All photographs, illustrations and tables should be placed in the text in their appro pri ate places where their descriptions are given.

\section{- References:}

o References should be indicated by superscript numbers consecutively in the text (e.g. "....has been reported1"; or as shown by $\mathrm{Akbar}^{2}$ ) in the order in which they are first mentioned and should be listed in numerical order on a separate sheet at the end of the article.

o References cited only in tables or legends or illustrations should be numbered in accordance with a sequence established by the first mention in the text.

o Titles of journals should be abbreviated according to Index Medicus or given in full.

o References must include: (i) all authors, surnames and initials (if there are 6 authors or fewer) or if there are more than 6 authors, the first three authors followed by et al; (ii) the full title of the paper; (iii) the abbreviated or full title of the journal; (iv) the year of publication; (v) the volume no; (vi) the first and last page numbers.

o Example: Khan NZ. A study of men tally handicapped children: aetiology and associated factors. Bangladesh Journal of Child Health, 1985; 9(2):102-08

\section{Manuscripts Submission:}

the manuscripts should be submitted to the editor/ executive editors with a covering letter, mentioning that the work has not been published or submitted for publication anywhere else. (Both soft and hard copies). We are also going to open a new pulse email address.

\section{Reprints for the authors:}

2 copies of original journal and five copies of each article will be provided to the corresponding author free of cost.

\section{Copy right:}

No part of the materials published in this journal may be reproduced, stored or transmitted without prior written permission of the editorial board. 